Supporting Information

\title{
Highly Stable Electrochemical Probe with Bidentate Thiols for Ratiometric Monitoring of Endogenous Polysulfide in Living Mouse Brains
}

Yinjie Qian, Limin Zhang*, and Yang Tian*

School of Chemistry and Molecular Engineering, East China Normal University, Dongchuan Road 500, Shanghai 200241, China.

Corresponding author: 1mzhang@chem. ecnu.edu.cn;

ytian@chem.ecnu.edu.cn 


\section{Table of contents:}

1. Experimental section.

2. Synthesis routes (Figure S1-S3).

3. ${ }^{1} \mathrm{H}$ NMR and ${ }^{13} \mathrm{C}$ NMR and mass spectra of PS1 (Figure S4-S5).

4. ${ }^{1} \mathrm{H}$ NMR and ${ }^{13} \mathrm{C}$ NMR and mass spectra of FP2 (Figure S6-S7).

5. ${ }^{1} \mathrm{H}$ NMR and ${ }^{13} \mathrm{C}$ NMR and mass spectra of FcBT (Figure S8-S9).

6. Liquid chromatography-mass spectrum of reaction of $\mathrm{H}_{2} \mathrm{~S}_{2}$ with FP2. (Figure S10).

7. FT-IR spectra of the reaction FP2 with $\mathrm{H}_{2} \mathrm{~S}_{\mathrm{n}}$ (Figure S11).

8. XPS spectra (Figure S12).

9. The relationship of the current density with scan rate (Figure S13).

10. Differential charge density diagram (Figure S14).

11. The desorption peaks of FP2 and FP1 (Figure S15).

12. SERS spectra of $\mathrm{Au} / \mathrm{FcBT}$ immersed in $5 \mathrm{mM}$ GSH for different times (Figure $\mathrm{S} 16$ ).

13. The electrochemical stability of FcBT (Figure S17).

14. XPS spectra of CFME/Au/FP2+FcBT electrode (Figure S18).

15. Response time (Figure S19).

16. Competition tests (Figure S20).

17. $\mathrm{pH}$ dependence of $\mathrm{CFME} / \mathrm{Au} / \mathrm{FP} 2+\mathrm{FcBT}$ electrode (Figure $\mathrm{S} 21$ ).

18. Reproducibility of CFME/Au/FP2+FcBT electrode (Figure S22).

19. TTC staining of brain tissue slices (Figure S23). 


\section{Experimental section.}

Materials and Reagents. Both silica gel plates and silica gel (300-400 mesh) were obtained Qingdao Ocean Chemicals (Qingdao, China). Dimethylsulfoxide-d6 (DMSO-d6), thioctic acid, paminophenol, $\quad$ 1-[Bis(dimethylamino)methylene]-1H-1,2,3-triazolo[4,5-b]pyridinium-3-oxid hexafluorophosphate (HATU), 2,4-dinitrofluorobenzene, 2-fluoro-5-nitrobenzoic acid, 3, 4dihydroxyphenylacetic acid, 3, 4-dihyhroxybenzoic, 4-hydroxy-phenethylamine, ascorbic Acid, dopamine (DA), cysteamine (TA), polystyrene-b-poly(oxyethyene) (PS-b-PEO), $\mathrm{HAuCl}_{4} \cdot 3 \mathrm{H}_{2} \mathrm{O}$, glucose, potassium superoxide and $30 \% \mathrm{H}_{2} \mathrm{O}_{2}$ were purchase from Sigma-Aldrich Co. Ltd (Shanghai, China). $\mathrm{NaNO}_{3}, \mathrm{NaNO}_{2}, \mathrm{NaClO}, \mathrm{GSH}, \mathrm{Na}_{2} \mathrm{SO}_{4}, \mathrm{Na}_{2} \mathrm{SO}_{3}, \mathrm{Na}_{2} \mathrm{~S}$ and other chemicals were purchased from Sinopharm Chemical Reagent Co. Itd. (Shanghai, China). All the solutions of metal ions were prepared from their chloride salts or nitrate salts, which were obtained from Aladdin reagent. All amino acids, including L-arginine (Ary), L-cysteine (Cys). L-glutamine (Glu), glycine (Gly), L-histidine (His), L-isoleucine (Iso), L-leucine (Leu), glutathione, GSH, GSSG, $\mathrm{Na}_{2} \mathrm{~S}_{2}$ and $\mathrm{Na}_{2} \mathrm{~S}_{4}$ aqueous solution was obtained and prepared according to the literature ${ }^{[\mathrm{S} 1-\mathrm{S} 3]}$. All reagents and chemicals were of analytical grade and were used without further purification. Double-distilled water obtained from a Millipore water purification system (Milli-Q, 18.2 M $\Omega$ ) was used in all experiments and were at room temperature.

In the selectivity test, different reactive oxygen species (ROS) and reactive nitrogen species (RNS) were produced as follows: superoxide solution $\left(\mathrm{O}_{2}{ }^{-}\right)$was prepared by adding $\mathrm{KO}_{2}(1 \mathrm{mg})$ to dry DMSO $(1 \mathrm{~mL})$ and stirring rigorously for $10 \mathrm{~min}$. Hydroxy radical $(\cdot \mathrm{OH})$ was generated through Fenton Chemistry $\left(\mathrm{Fe}^{2+} / \mathrm{H}_{2} \mathrm{O}_{2}=1: 6\right)$. Singlet oxygen $\left({ }^{1} \mathrm{O}_{2}\right)$ was generated was generated in situ by addition of the $\mathrm{HClO}$ into a solution containing excess of $\mathrm{H}_{2} \mathrm{O}_{2}\left(\mathrm{ClO}^{-} / \mathrm{H}_{2} \mathrm{O}_{2}=1: 5\right)$. Nitroxy (HNO) was generated from solution of Angeli's salt $(10 \mathrm{mM})$. Nitric Oxide $\left(\mathrm{NO}_{2}\right)$ was derived from SNAP, Peroxynitrite (ONOO-) was provided by $\mathrm{KNO}_{2}(10 \mu \mathrm{M})$ and $\mathrm{H}_{2} \mathrm{O}_{2}(10 \mu \mathrm{M})$ in $0.6 \mathrm{M} \mathrm{HCl}$ at $0{ }^{\circ} \mathrm{C}$.

Apparatus and Instruments. ${ }^{1} \mathrm{H}$ NMR and ${ }^{13} \mathrm{C}$ NMR spectra were recorded on a Bruker AVANCE IIITM 500 Spectrometer. HPLC-MS measurements were conducted on a Hewlett Packard series 
1100 HPLC (column: Agilent Pre-C18, $5 \mu \mathrm{m}, 4.6 \times 250 \mathrm{~mm}$ ). Infrared spectra (IR) were obtained by Infrared spectrometer (Thermo Scientific Nicolet iS50). Ultraviolet spectrum was performed on a UH5300 UV-Vis spectrophotometer (Hitachi, Japan). The SEM image and energy dispersive EDX were taken using filed emission gun Hitachi S-4800 (Japan) scanning electron microscope operated at $4.0 \mathrm{kV}$. The transmission electron microscopy was acquired by High Resolution Transmission Electron Microscopy (HRTEM, JEOL JEM-2010F, 200 kV). XPS characterization was performed on a PHI-5000ESCA system (Perkin Elmer) with a monochromatic Mg K $\alpha$ source (1253.6 eV) photon energy. Electrochemical experiment was performed on an electrochemical workstation (CHI 660D, Chenhua Co. Ltd, Shanghai, China) with a standard three-electrode system consisting of a commercial $\mathrm{Ag} / \mathrm{AgCl}$ electrode as reference electrode connected with a $\mathrm{KCl}$ salt bridge and a platinum wire as the counter electrode.

Synthesis of PS1. Firstly, sulfur dichloride $\left(\mathrm{SOCl}_{2}, 0.75 \mathrm{~mL}\right)$ and dry dimethylformamide (DMF, $20 \mathrm{~mL}$ ) were added to a suspension of 2-fluoro-5-nitrobenzoic acid $(1.85 \mathrm{~g}, 1 \mathrm{mM})$ in anhydrous toluene $(10 \mathrm{~mL})$ at room temperature. The mixture was heated under reflux for $5 \mathrm{~h}$, then the mixture was concentrated in vacuo, and washed and concentrated again with dry $\mathrm{CH}_{2} \mathrm{Cl}_{2}$ for three times. The resulting residue was dissolved in $2 \mathrm{~mL}$ dry $\mathrm{CH}_{2} \mathrm{Cl}_{2}$ for the next step without further purification. Next, the solution was added dropwise manner to the stirred mixture of 3, 4-dihydroxybenzoic $(0.77$ $\mathrm{g}, 0.5 \mathrm{mM}), \mathrm{dry} \mathrm{Et}_{3} \mathrm{~N}(500 \mathrm{~mL})$ in an ice bath. The resulting mixture was stirred at room temperature for $12 \mathrm{~h}$, then the resulting precipitate was filtered and washed with $50 \mathrm{~mL}$ methanol for three times, and dried at room temperature for $18 \mathrm{~h}$, PS1 was afforded $1.95 \mathrm{~g}$ as yellow solid in $80 \%$ field. ${ }^{1} \mathrm{H}$ NMR (500 MHz, DMSO- $\left.d_{6}\right) \delta 13.41(\mathrm{~s}, 1 \mathrm{H}), 8.73(\mathrm{~d}, 2 \mathrm{H}), 8.57(\mathrm{~m}, 2 \mathrm{H}), 8.21(\mathrm{~d}, 1 \mathrm{H}), 8.06(\mathrm{dd}, 1 \mathrm{H})$, 7.81-7.63 (m, 3H). ${ }^{13} \mathrm{C}$ NMR (500 MHz, DMSO- $\left.d_{6}\right) \delta 166.28,163.86,163.79,159.72,159.68$, $159.45,159.42,145.14,144.22,144.20,144.18,144.16,141.61,131.96,131.87,131.78,131.69$, $130.58,129.01,128.13,125.43,124.57,119.88,119,78,119.69,119.59,118.37,118.27,118.11$, 118.02. HRMS m/z: 487.0231. [M-H]-; calcd for $\mathrm{C}_{21} \mathrm{H}_{11} \mathrm{~F}_{2} \mathrm{~N}_{2} \mathrm{O}_{10}$ : 487.0231 .

Methods. The first-principles ${ }^{[\mathrm{S4}, \mathrm{S5}]}$ was used to perform all Spin-polarization density functional theory (DFT) calculations within the generalized gradient approximation (GGA) using the Perdew- 
Burke-Ernzerhof (PBE) formulation ${ }^{[\mathrm{S} 6]}$. The projected augmented wave (PAW) potentials ${ }^{[\mathrm{S} 7, \mathrm{~S} 8]}$ was chosen to describe the ionic cores and take valence electrons into account using a plane wave basis set with a kinetic energy cutoff of $400 \mathrm{eV}$. Partial occupancies of the Kohn-Sham orbitals were allowed using the Gaussian smearing method and a width of $0.05 \mathrm{eV}$. The electronic energy was considered self-consistent when the energy change was smaller than $10^{-4} \mathrm{eV}$. A geometry optimization was considered convergent when the energy change was smaller than $0.05 \mathrm{eV} \AA^{-1}$. The vacuum spacing in a direction perpendicular to the plane of the structure is $26 \AA$. The Brillouin zone integration is performed using $2 \times 2 \times 1$ Monkhorst-Pack k-point sampling for a structure. Finally, the adsorption energies (Eads) were calculated as Eads= Ead/sub -Ead -Esub, where Ead/sub, Ead, and Esub are the total energies of the optimized adsorbate/substrate system, the adsorbate in the structure, and the clean substrate, respectively. 


\section{Synthesis Routes.}

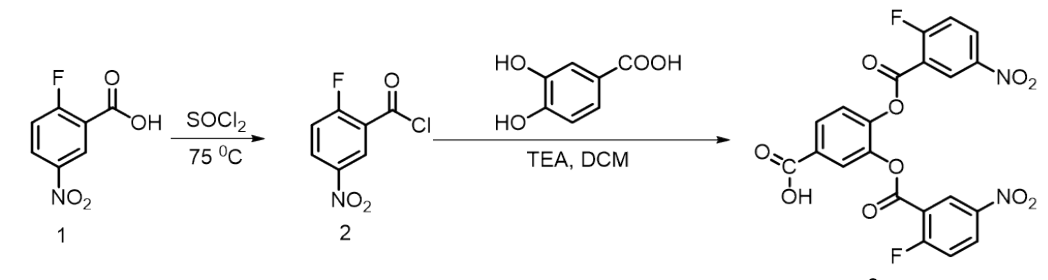

Figure S1. Synthesis routes of probe PS1.

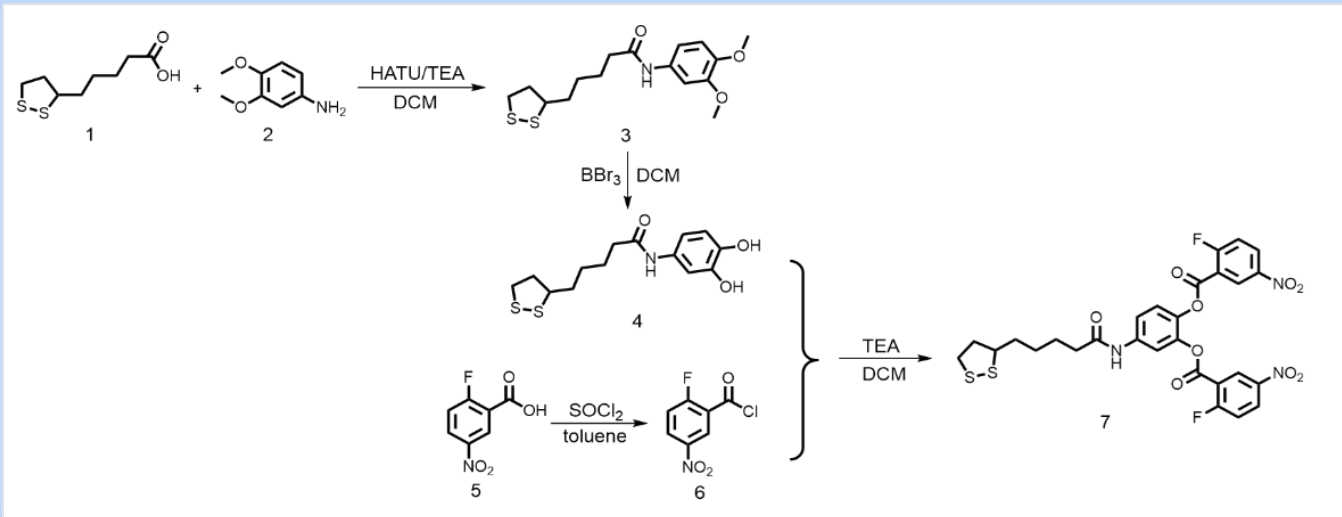

Figure S2. Synthesis routes of probe FP2.

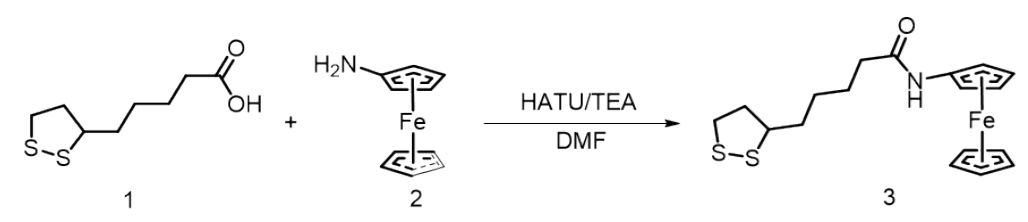

Figure S3. Synthesis routes of inner reference probe of FcBT. 


\section{3. ${ }^{1} \mathrm{H}$ NMR and ${ }^{13} \mathrm{C}$ NMR and mass spectra of PS1.}
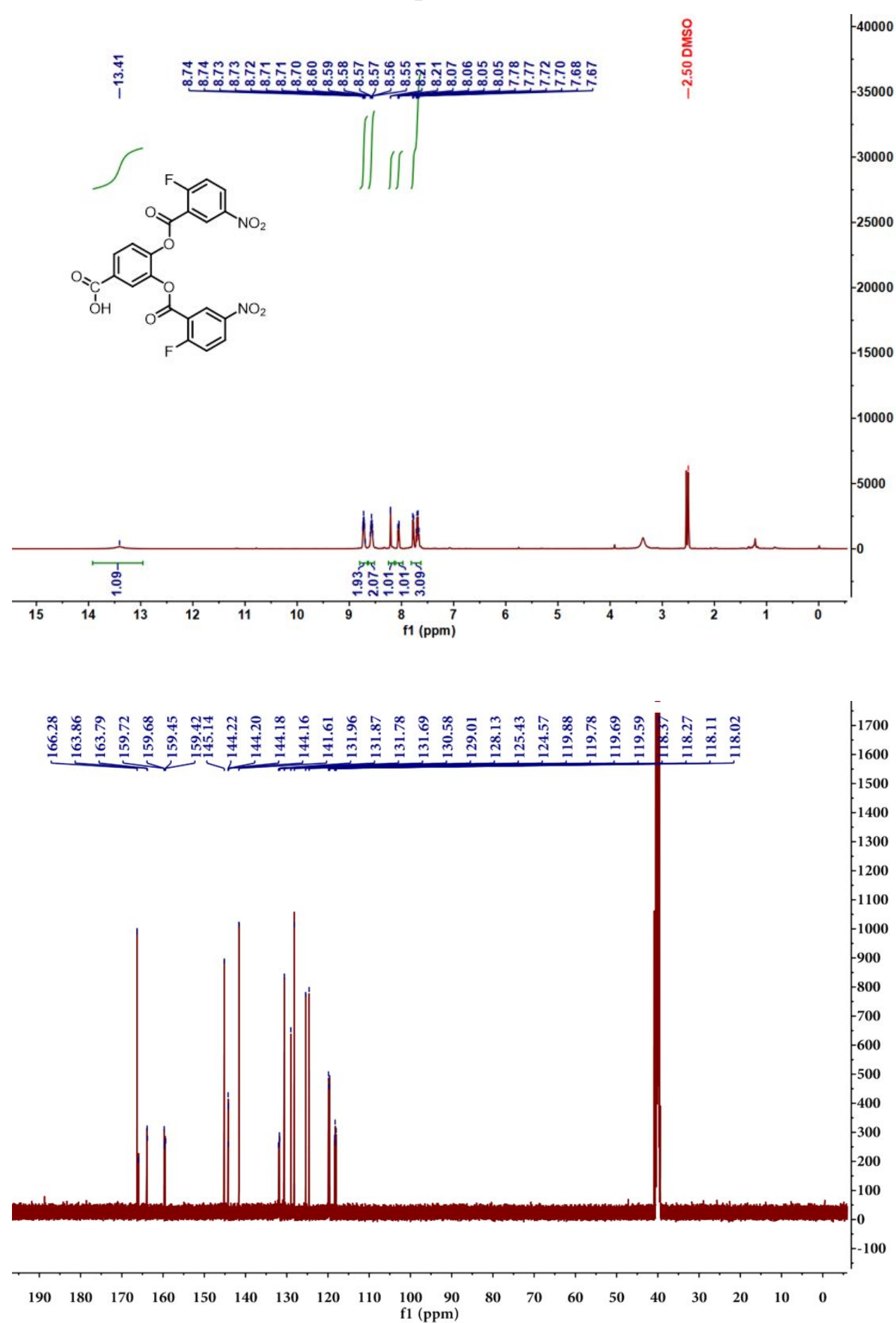

Figure S4. ${ }^{1} \mathrm{H}$ NMR, ${ }^{13} \mathrm{C}$ NMR results of PS1. 


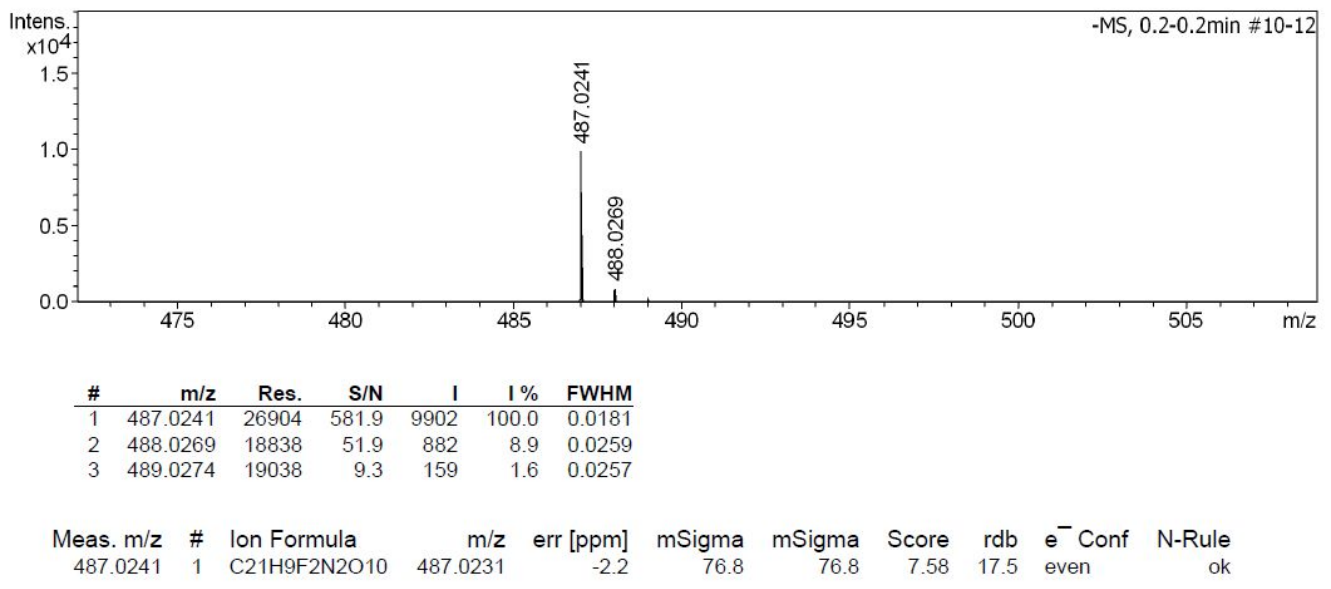

Figure S5. Mass spectrum of PS1. 
4. ${ }^{1} \mathrm{H}$ NMR, ${ }^{13} \mathrm{C}$ NMR and mass spectrum of FP2.
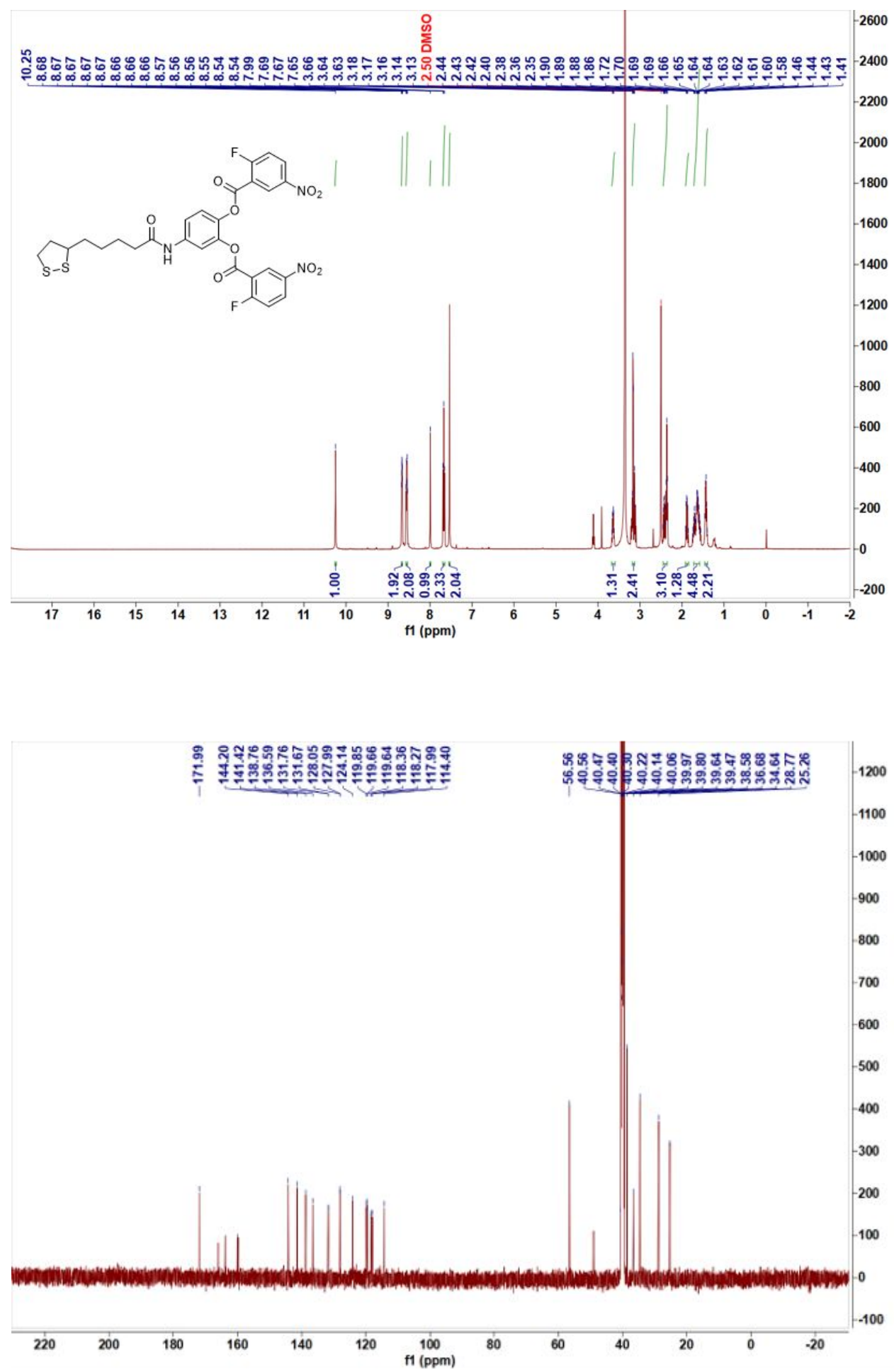

Figure S6. ${ }^{1} \mathrm{H}$ NMR, ${ }^{13} \mathrm{C}$ NMR results of FP2. 


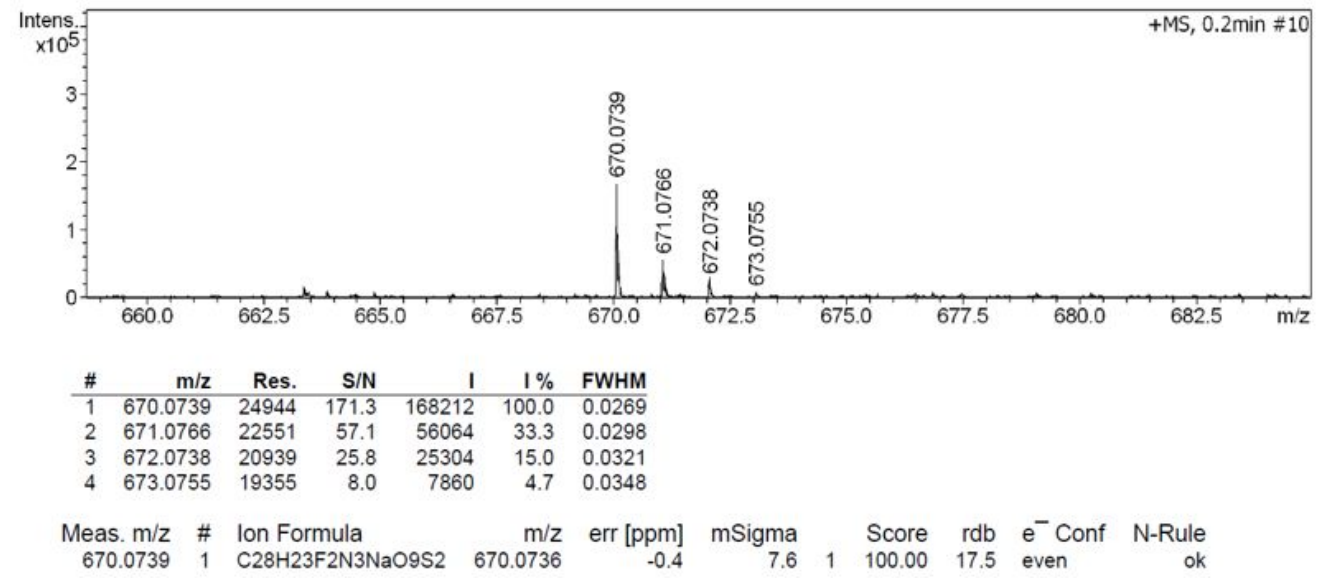

Figure S7. Mass spectrum of FP2. 
5. ${ }^{1} \mathrm{H}$ NMR, ${ }^{13} \mathrm{C}$ NMR and mass spectrum of spectrum of FcBT.
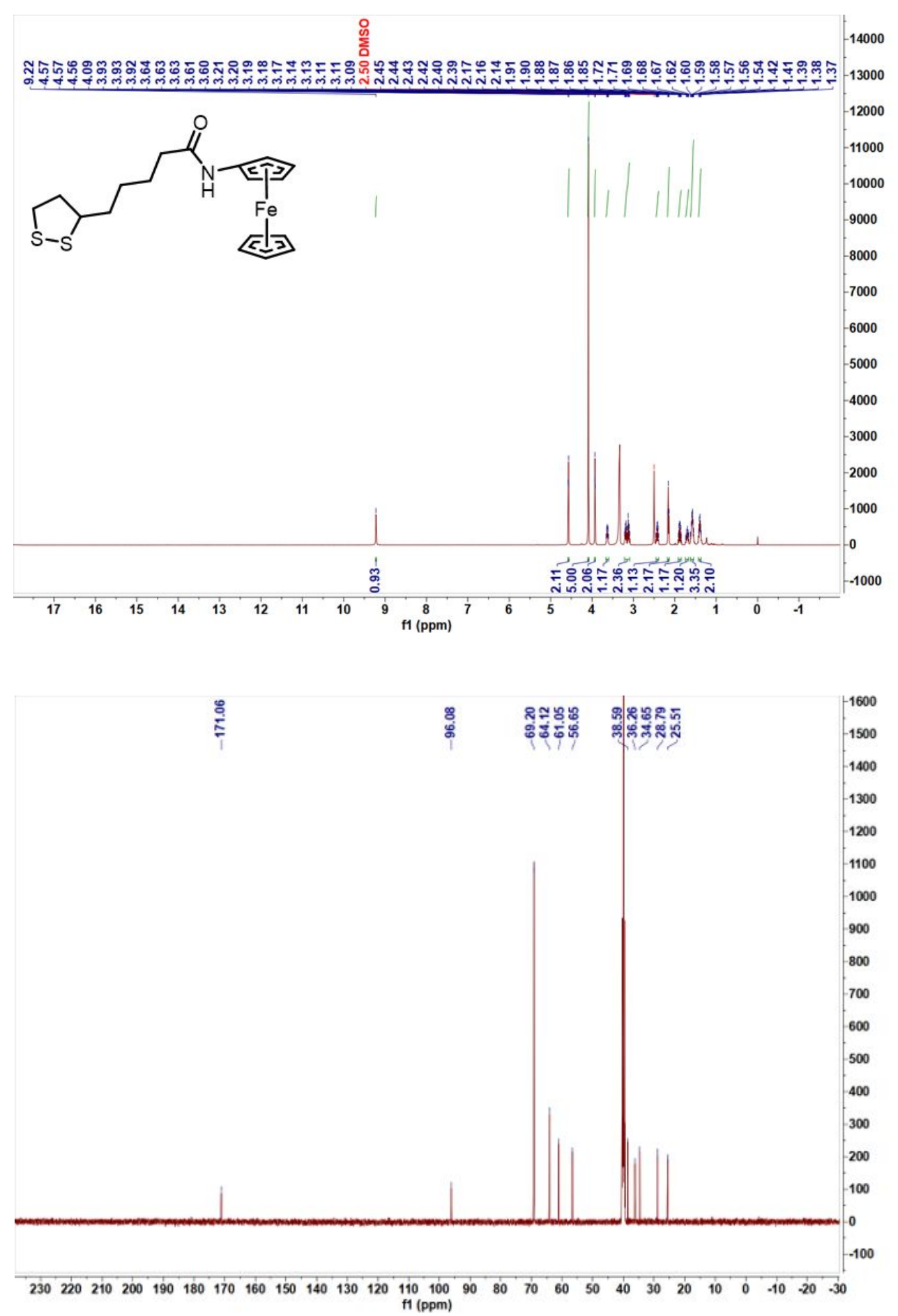

Figure S8. ${ }^{1} \mathrm{H}$ NMR, ${ }^{13} \mathrm{C}$ NMR results of $\mathrm{FcBT}$. 


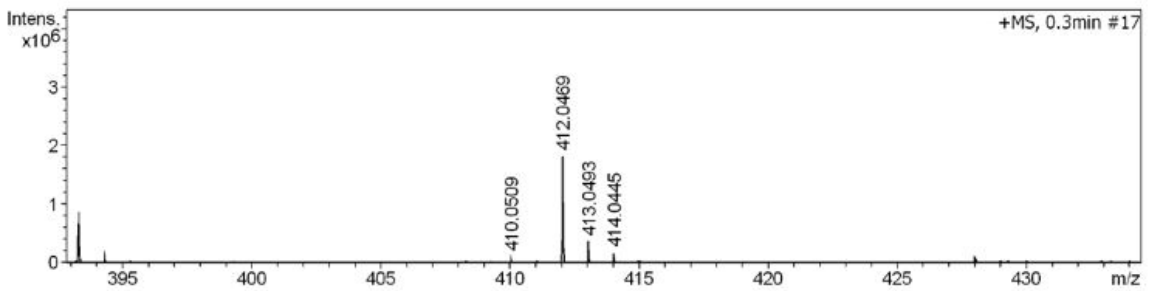

\begin{tabular}{|c|c|c|c|c|c|c|c|c|c|c|c|c|}
\hline \# & $\mathrm{m} / \mathrm{z}$ & Res. & $S / N$ & 1 & $1 \%$ & FWHM & & & & & & \\
\hline 1 & 410.0509 & 21838 & 117.6 & 97024 & 5.4 & 0.0188 & & & & & & \\
\hline 2 & 411.0496 & 14990 & 33.3 & 27476 & 1.5 & 0.0274 & & & & & & \\
\hline 3 & 412.0469 & 34091 & 2195.6 & 1810940 & 100.0 & 0.0121 & & & & & & \\
\hline 4 & 413.0493 & 25845 & 440.6 & 363556 & 20.1 & 0.0160 & & & & & & \\
\hline 5 & 414.0445 & 21235 & 193.0 & 159352 & 8.8 & 0.0195 & & & & & & \\
\hline 6 & 415.0455 & 19268 & 38.6 & 31884 & 1.8 & 0.0215 & & & & & & \\
\hline & $\mathrm{m} / \mathrm{z}$ & Ion $\mathrm{F}$ & mula & & $1 / 2$ & [ppm] & mSigma & & Score & $\mathrm{rdb}$ & $e^{-}$Conf & \\
\hline 41 & 0469 & $\mathrm{C} 18 \mathrm{H} 2$ & $\mathrm{FeNNaOS}$ & 412.046 & & -1.5 & 19.9 & 2 & 100.00 & 7.5 & & \\
\hline
\end{tabular}

Figure S9. Mass spectrum of FcBT. 


\section{Liquid chromatography-mass spectrum of reaction of $\mathrm{H}_{2} \mathrm{~S}_{2}$ with FP2.}
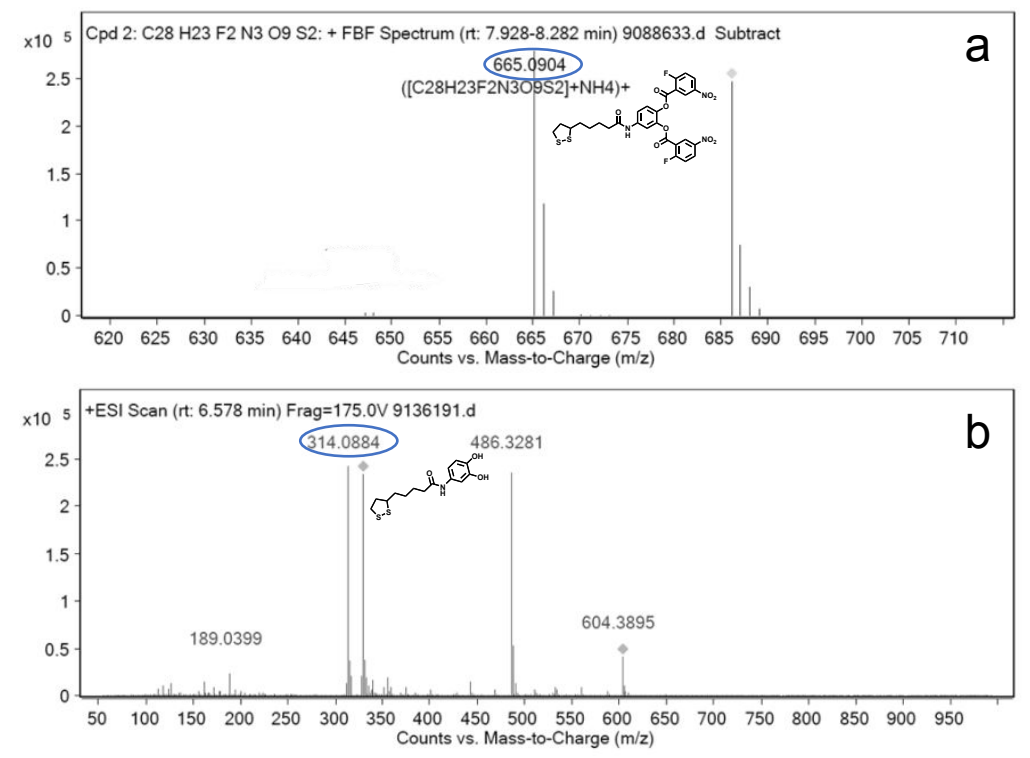

Figure S10. LC-MS analysis of (a) $2.5 \mu \mathrm{M}$ FP2 solution and (b) $2.5 \mu \mathrm{M}$ FP2 solution reacted with $5 \mu \mathrm{M} \mathrm{Na} \mathrm{S}_{2}$. The $\mathrm{m} / \mathrm{z}$ peaks at 665.0904 and 314.0884 were assigned to be FP2 and N-(3,4dihydroxyphenyl)-5-(1,2-dithiolan-3-yl)-pentanamide.

\section{FT-IR spectra of the reaction FP2 with $\mathrm{H}_{2} \mathrm{~S}_{n}$}

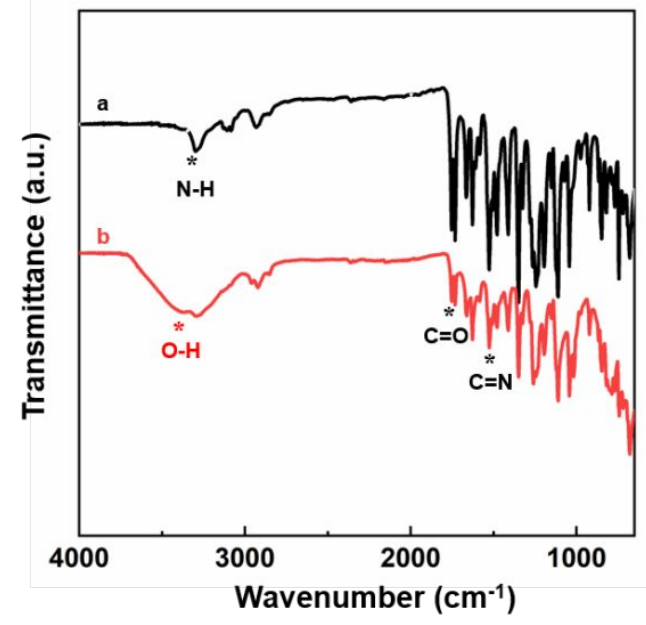

Figure S11. FT-IR spectra of (a) FP2 and (b) the products of the reaction between FP2 solution and $\mathrm{Na}_{2} \mathrm{~S}_{2}$. 


\section{XPS spectra.}
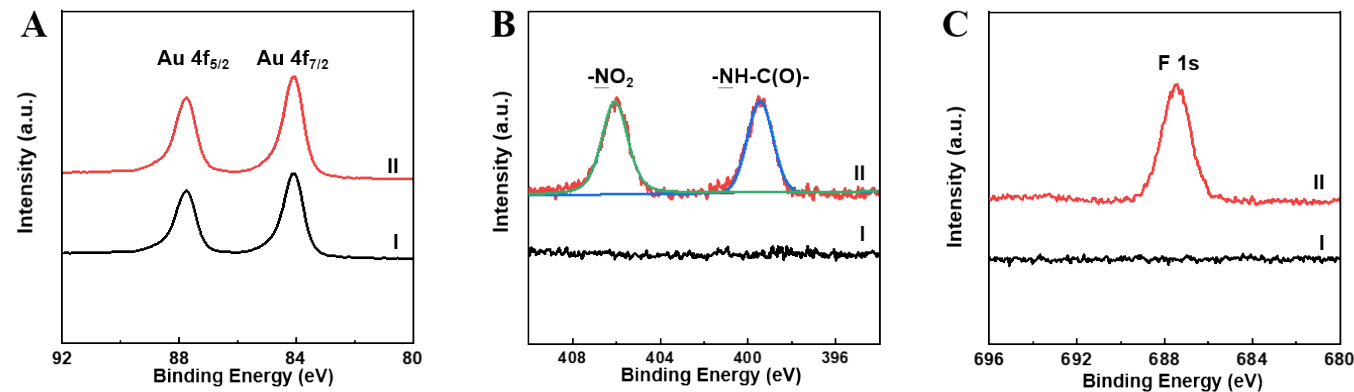

Figure S12. XPS spectra for (A) Au 4f $\mathrm{f}_{7 / 2}$ and $4 \mathrm{f}_{5 / 2}$, (B) N 1s, (C) F 1s at (I) bare Au electrode, (II) $\mathrm{Au} / \mathrm{FP} 2$ electrode.

\section{The relationship of the current density with scan rate.}
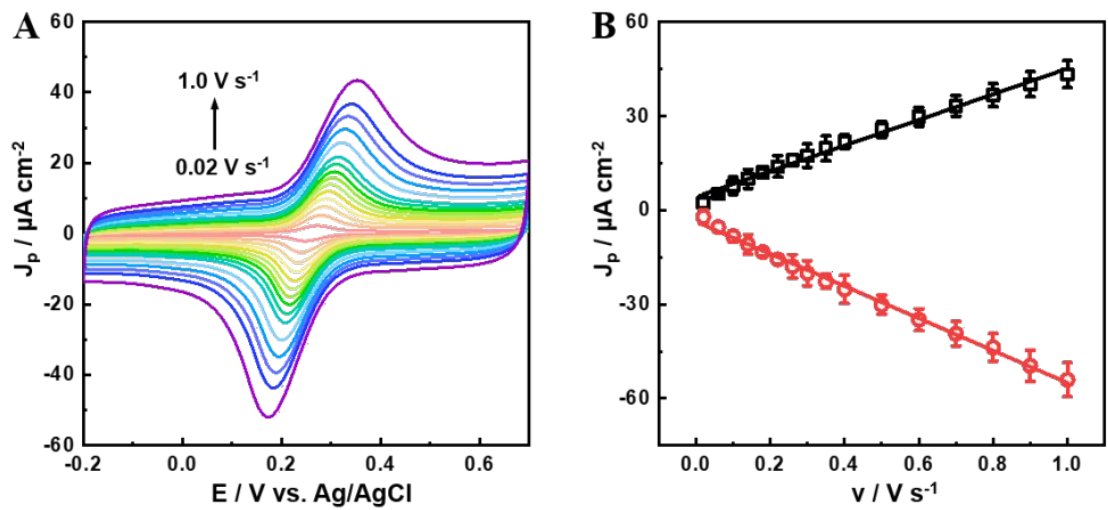

Figure S13. (A) CVs obtained at $\mathrm{Au} / \mathrm{FP} 2$ in $5 \mathrm{mM} \mathrm{Na}_{2} \mathrm{~S}_{2}$ at scan rates from $0.02 \mathrm{~V} \mathrm{~s}^{-1}$ to $1.0 \mathrm{~V} \mathrm{~s}^{-1}$. (B) The linear relationship between peak current intensity and scan rate. The error bars indicate standard deviations ( $n=3$, S.D.). 


\section{Differential charge density diagram}

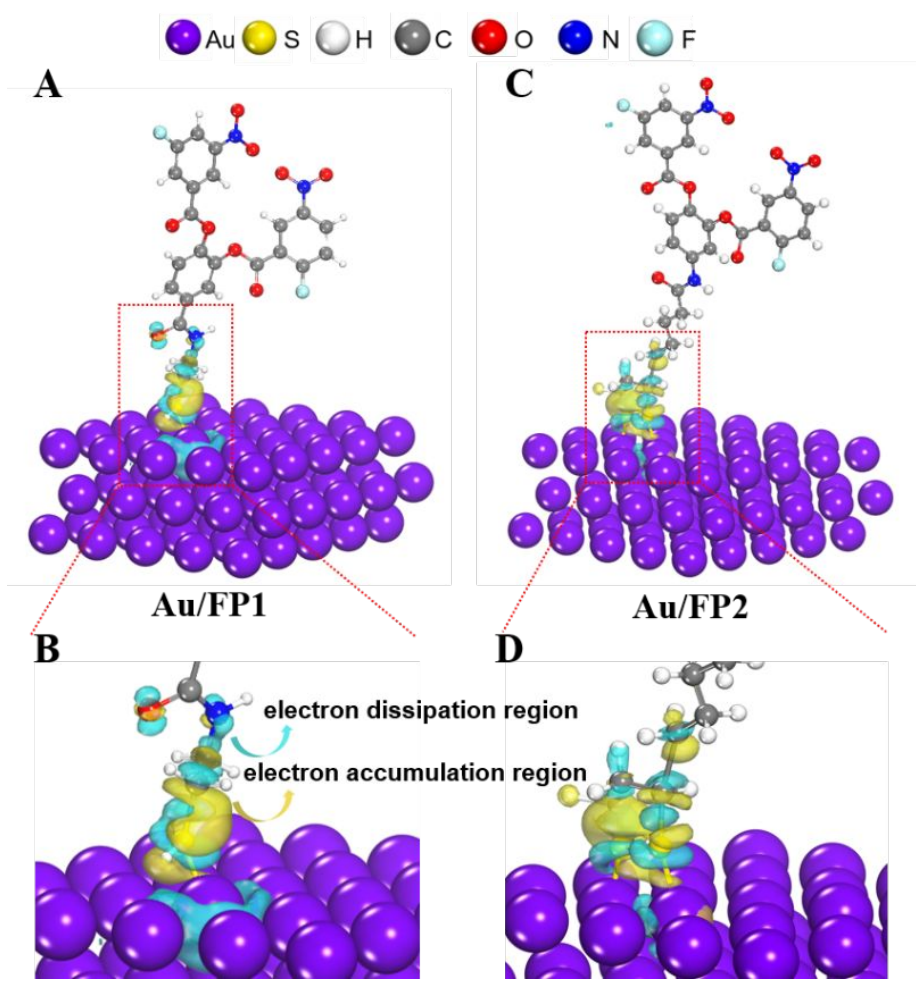

Figure S14. (A-B) Differential charge density diagram obtained from (A) Au/FP1 and (B) an enlarged diagram. (C-D) Differential charge density diagram obtained from (C) Au/FP2 and (D) an enlarged diagram. The yellow represents the electron accumulation region and blue represents the electron dissipation region. 


\section{The desorption peaks of FP2 and FP1.}
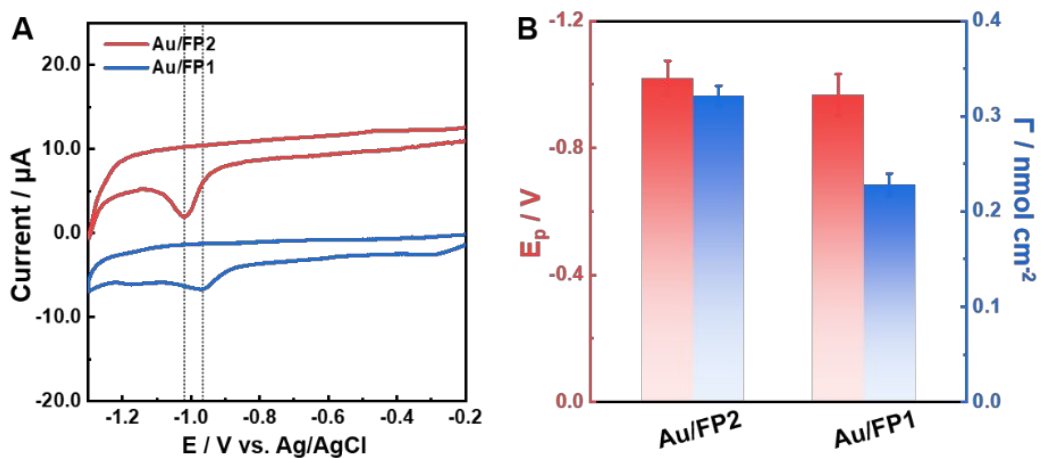

Figure S15. (A) Cyclic voltametric curves for the reductive desorption of FP2 and FP1 at Au electrode in $0.5 \mathrm{M} \mathrm{KOH}$. Scan rate is $20 \mathrm{mV} \mathrm{s}^{-1}$. (B) Comparison of desorption peak potential and the surface adsorption coverages of probes at electrode surface.

\section{SERS spectra of $\mathrm{Au} / \mathrm{FcBT}$ immersed in $5 \mathrm{mM} \mathrm{GSH}$ for different times.}
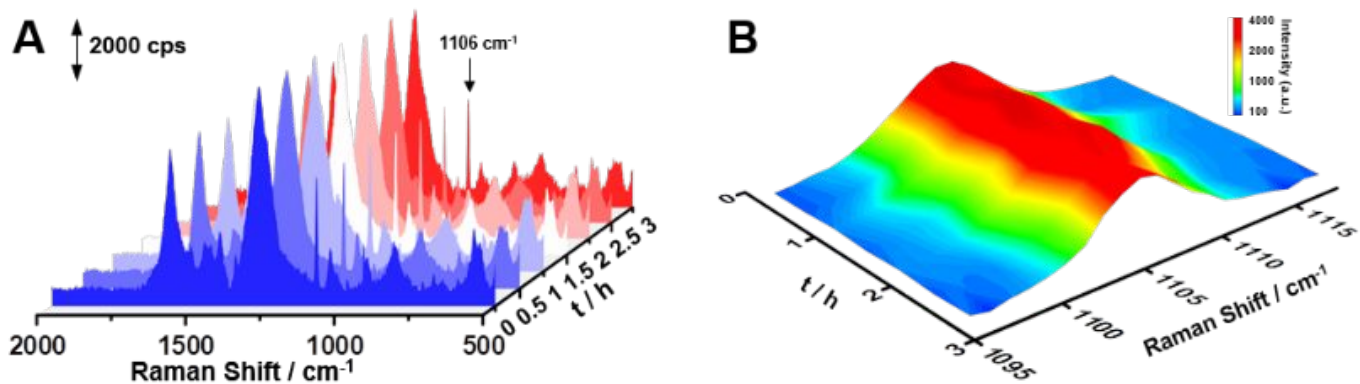

Figure S16. (A) SERS spectra of $\mathrm{Au} / \mathrm{FcBT}$ immersed in $5 \mathrm{mM} \mathrm{GSH}$ for different times and (B) the corresponding enlarged SERS mapping of intensity as marked in A. 


\section{The electrochemical stability of FcBT.}

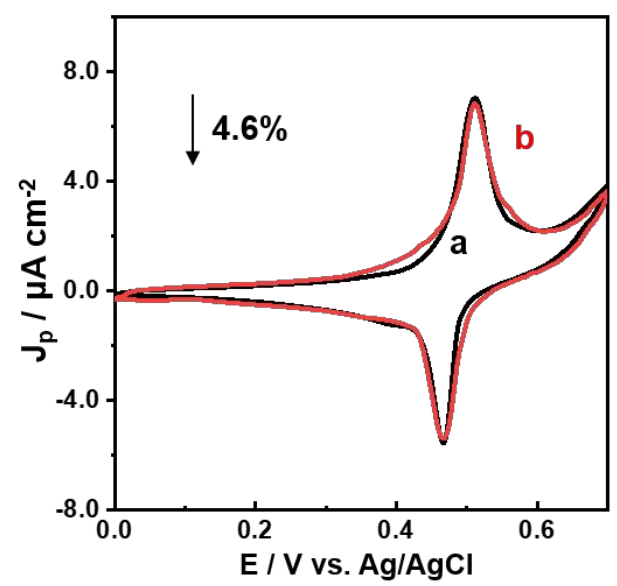

Figure S17. CVs obtained at $\mathrm{Au} / \mathrm{FcBT}$ in $\mathrm{aCSF}$ (a) before and (b) after consecutive scanning for 50 cycles. Scan rate: $100 \mathrm{mV} \mathrm{s}^{-1}$.

\section{XPS spectra of CFME/Au/FP2+FcBT electrode.}
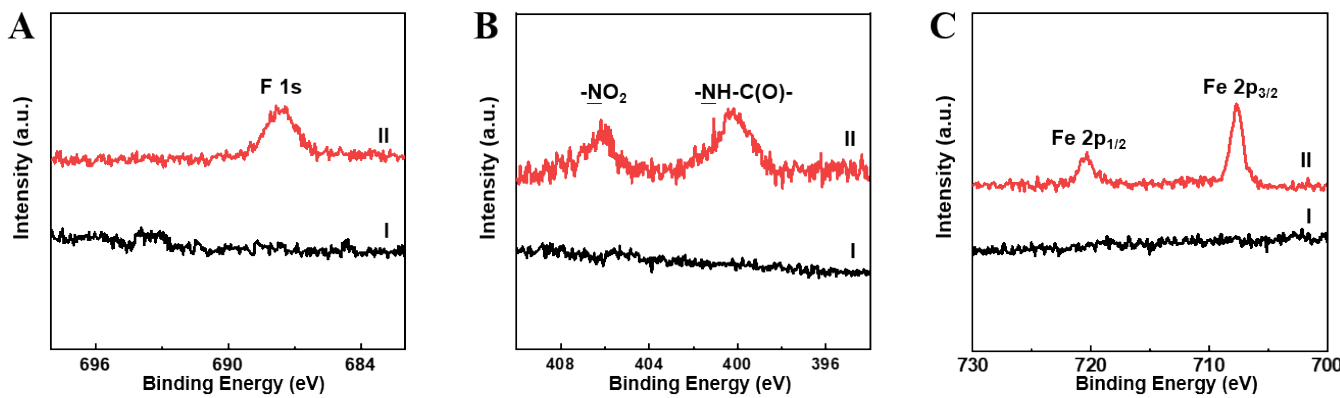

Figure S18. XPS spectra for (A) $F 1 s$, (B) $N 1 \mathrm{~s}$ and (C) $\mathrm{Fe} 2 \mathrm{p}_{3 / 2}$ and $\mathrm{Fe} 2 \mathrm{p}_{1 / 2}$ at $\mathrm{CFME} / \mathrm{Au} / \mathrm{FP} 2+\mathrm{FcBT}$ electrode. 


\section{Response time.}

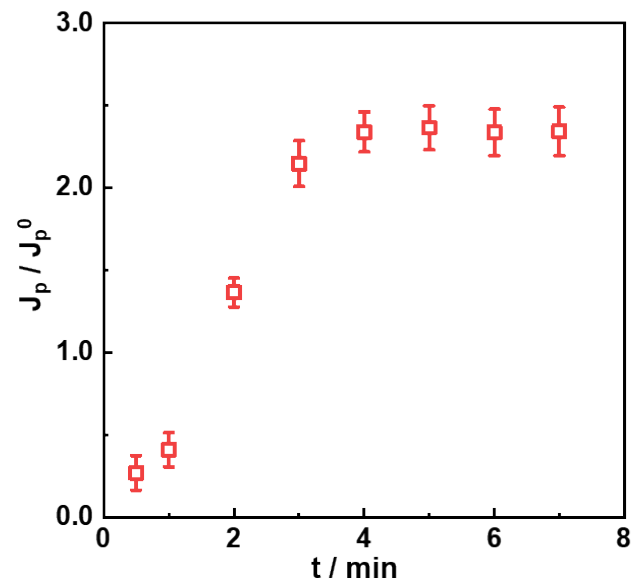

Figure S19. Time-dependent $j_{\mathrm{p}} / j_{\mathrm{p}}{ }^{0}$ changes of CFME/Au/FP2 $+\mathrm{FcBT}$ electrode in aCSF solution ( $\mathrm{pH}$ 7.4) in the presence of $5 \mu \mathrm{M} \mathrm{Na}_{2} \mathrm{~S}_{2}$. The error bars indicate standard deviations $(\mathrm{n}=3$, S.D.). 


\section{Competition tests.}
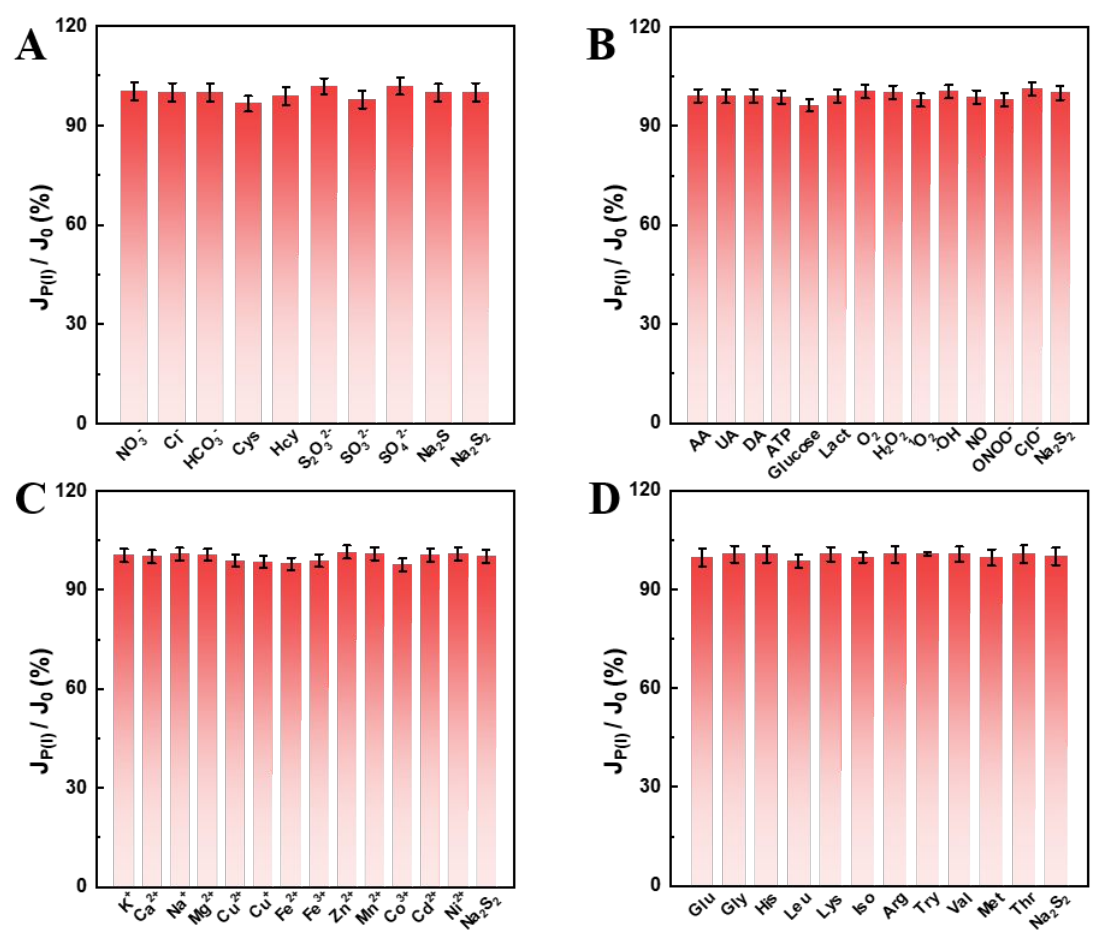

Figure S20. (A-D) Competition tests of CFME/Au/FP2+FcBT for $\mathrm{Na}_{2} \mathrm{~S}_{2}$ and in the presence of (A) anion and sulfide-containing species obtained from $j_{\mathrm{p}(\mathrm{I})} / j_{0}\left(\mathrm{NO}_{3}^{-}, \mathrm{Cl}^{-}, \mathrm{HCO}_{3}{ }^{-}, \mathrm{Cys}, \mathrm{Hcy}, \mathrm{S}_{2} \mathrm{O}_{3}^{2-}, \mathrm{SO}_{3}{ }^{2-}\right.$, $\mathrm{SO}_{4}{ }^{2-}, \mathrm{Na}_{2} \mathrm{~S}, 5 \mu \mathrm{M}$ for $\mathrm{Na}_{2} \mathrm{~S}_{2}, 10 \mu \mathrm{M}$ for other species), (B) neurotransmitters and ROS (AA, UA, DA, ATP, glucose, Lact, $\mathrm{O}_{2}, \mathrm{H}_{2} \mathrm{O}_{2},{ }^{1} \mathrm{O}_{2}, \bullet \mathrm{OH}, \mathrm{ONOO}^{-}, \mathrm{ClO}^{-}(300 \mu \mathrm{M}$ for AA, $1 \mu \mathrm{M}$ for UA, DA, and ATP, $200 \mu \mathrm{M}$ for glucose, and other species' are $10 \mu \mathrm{M}$ ), (C) metal ions which are $\mathrm{K}^{+}, \mathrm{Ca}^{2+}$, $\mathrm{Na}^{+}, \mathrm{Mg}^{2+}, \mathrm{Cu}^{2+}, \mathrm{Cu}^{+}, \mathrm{Fe}^{2+}, \mathrm{Fe}^{3+}, \mathrm{Zn}^{2+}, \mathrm{Mn}^{2+}, \mathrm{Co}^{2+}, \mathrm{Cd}^{2+}, \mathrm{Ni}^{2+}\left(100 \mathrm{mM}\right.$ for $\mathrm{Na}^{+}, \mathrm{K}^{+}, 1 \mathrm{mM}$ for $\mathrm{Ca}^{2+}$ and $\mathrm{Mg}^{2+}$, and the concentrations of others metal ions are all $10 \mu \mathrm{M}$ ), (D) amino acids which are 10 mM for Glu, Gly, His, Leu, Lys, Iso, Arg, Try, Val, Met, Thr. The error bars indicate standard deviations ( $\mathrm{n}=3$, S.D.). 
17. pH dependence of CFME/Au/FP2+FcBT electrode.

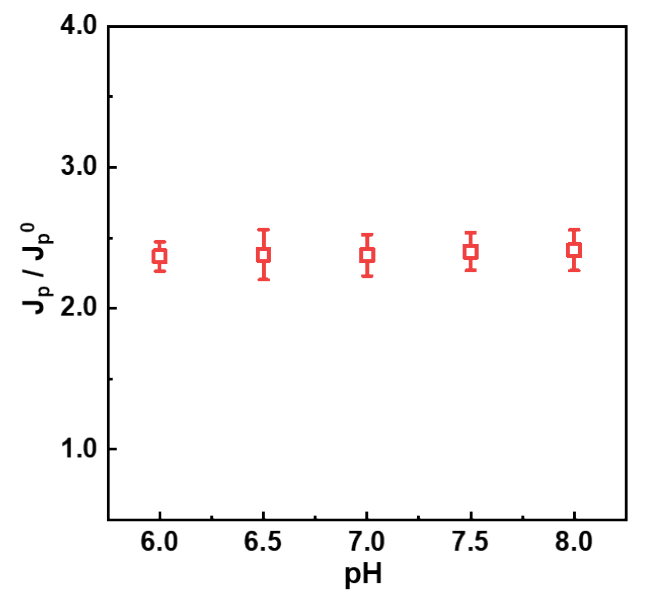

Figure S21. Peak current density ratios $\left(j_{\mathrm{p}} / j_{\mathrm{p}}{ }^{0}\right)$ obtained at $235 \mathrm{mV}$ and $516 \mathrm{mV}$ in aCSF solution (pH 7.4) containing $5 \mu \mathrm{M} \mathrm{Na}_{2} \mathrm{~S}_{2}$ with different $\mathrm{pH}$, respectively. The error bars indicate standard deviations ( $\mathrm{n}=3$, S.D.).

\section{Reproducibility of CFME/Au/FP2+FcBT electrode.}

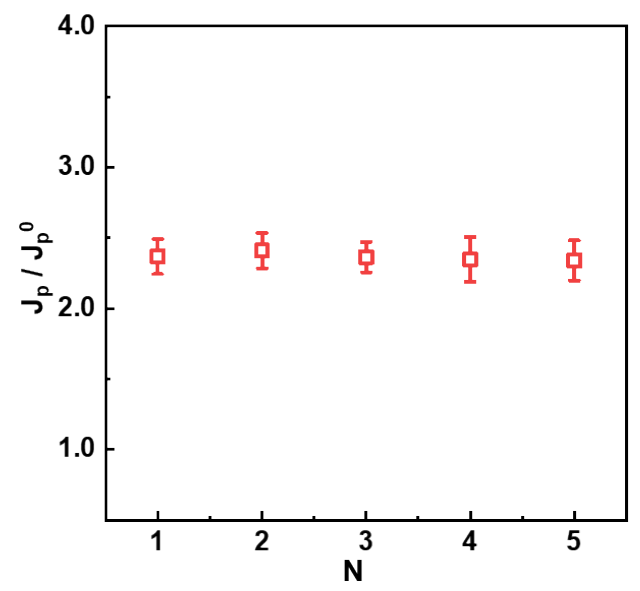

Figure S22. Reproducibility test for five $\mathrm{CFME} / \mathrm{Au} / \mathrm{FP} 2+\mathrm{FcBT}$ electrodes monitored in aCSF solution ( $\mathrm{pH}$ 7.4) containing $5 \mu \mathrm{M} \mathrm{Na}_{2} \mathrm{~S}_{2}$. The error bars indicate standard deviations $(\mathrm{n}=3$, S.D.). 
19. TTC staining of brain tissue slices.

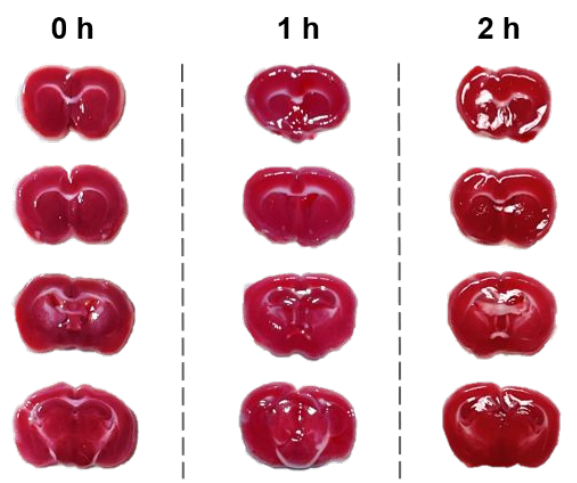

Figure S23. TTC staining of brain tissue slices after the microelectrode immersed into live brain for 0,1 and $2 \mathrm{~h}$, respectively. 


\section{References}

S1. Takata, T.; Saeki, K.; Makita, Y.; Yamada, N.; Kihara, N. Aromatic Hydrocarbon-Catalyzed Direct Reaction of Sulfur and Sodium in a Heterogeneous System: Selective and Facile Synthesis of Sodium Monosulfide and Disulfide. Inorg. Chem. 2003, 42, 3712-3714.

S2. Yamada, N.; Furukawa, M.; Nishi, M.; Takata, T. Direct Preparation of Anhydrous Sodium Oligosulfides from Metal Sodium and Elemental Sulfur in Aprotic Organic Media Directed toward Synthesis of Silane Coupling Agent. Chem. Lett. 2002, 31, 454-455.

S3. Stensaas, K. L.; Brownell, A. S.; Ahuja, S.; Harriss, J. K.; Herman, S. R. Competitive Oxidations of Dibenzyl Trisulfide vs. Substituted Aryl Polysulfides. J. Sulfur Chem. 2008, 29, 433-443.

S4. Kresse, G.; Furthmüller, J. Efficiency of Ab-Initio Total Energy Calculations for Metals and Semi-Conductors Using a Plane-Wave Basis Set. Comput. Mater. Sci. 1996, 6, 15-50.

S5. Kresse, G.; Furthmüller, J. Efficient Iterative Schemes for Ab Initio Total-Energy Calculations Using a Plane-Wave Basis Set. Phys. Rev. B. 1996, 54, 11169-11186.

S6. Perdew, J. P.; Burke, K.; Ernzerhof, M. Generalized Gradient Approximation Made Simple. Phys. Rev. Lett. 1996, 77, 3865-3868.

S7. Kresse, G.; Joubert, D. From Ultrasoft Pseudopotentials to the Projector Augmented-Wave Method. Phys. Rev. B. 1999, 59, 1758-1775.

S8. Blochl, P. E. Projector Augmented-Wave Method. Phys. Rev. B. 1994, 50, 17953-17979. 